\title{
Pengembangan Metode Percepatan Penjadwalan Pada Keterlambatan Proyek EPC Di Fase Pelaksanaan Dengan Analisa "What If"
}

\author{
Pratiwi Setyaning Putri ${ }^{1}$; Hastanto SM $^{2}$ \\ ${ }^{1,2}$ Sekolah Tinggi Teknik PLN \\ 1'pratiwi@sttpln.ac.id
}

\begin{abstract}
This study aims to analyze corrective actions that can be done if there is a project delay in one of the activities. Data collection techniques are carried out by observation. The gap between the actual and planned scheduling level (productivity gap) is a problem that must be evaluated and the root cause that causes the decline in work productivity is sought. After further evaluation, it is planned to retarget the acceleration that will be achieved both in the short and long term. The acceleration method for scheduling the duration of the project is done by the critical path method or CPM (Critical Path Method) for further development of corrective actions that can be done to overcome the delay in the duration of the project.
\end{abstract}

Keywords: Critical Path Method, Project Delay, EPC

\begin{abstract}
ABSTRAK
Penelitian ini bertujuan untuk menganalisa tindakan korektif yang dapat dilakukan apabila terjadi keterlambatan proyek pada salah satu aktivitas. Teknik pengumpulan data dilakukan dengan observasi. Kesenjangan yang terjadi antara tingkat penjadwalan aktual dan rencana (productivity gap) merupakan masalah yang harus dievaluasi dan dicari akar penyebab yang menimbulkan turunya produktivitas kerja. Setelah dilakukan evaluasi selanjutnya dapat direncanakan kembali target percepatan yang akan dicapai baik dalam jangka pendek maupun jangka panjang. Metode percepatan pada penjadwalan durasi proyek dilakukan dengan metode jalur kritis atau CPM (Critical Path Method) untuk selanjutnya dilakukan pengembangan tindakan korektif yang dapat dilakukan untuk mengatasi keterlambatan durasi proyek.
\end{abstract}

Kata kunci: Critical Path Method, Keterlambatan Proyek, EPC 


\section{PENDAHULUAN}

\subsection{Latar Belakang}

Persaingan usaha jasa konstruksi pada era globalisasi yang sangat ketat, dengan hadirnya kontraktor asing ke pasar konstruksi juga tuntutan transparansi sebagai ciri dari globalisasi akan sangat menguat. Dengan demikian kita tidak bisa menghindar dari kondisi global. Maka dari itu pola berpikir lokal akan berubah menjadi pola berpikir global [1]. Terjadinya suatu keterlambatan pelaksanaan proyek konstruksi dapat disebabkan oleh kontraktor atau faktor lainnya yang mempengaruhi pelaksanaan proyek. Keterlambatan juga bisa disebabkan oleh pihak owner, perencana, pihak-pihak lainnya ataupun faktor kondisi alam yang tidak diharapkan [2]. Pembahasan dari 7 (tujuh) faktor dominan yang berpengaruh pada kinerja waktu pada pelaksanaan konstruksi gedung secara swakelola pada proyek pengembangan SMK di Aceh dapat dikelompokkan ke dalam 3 (tiga) kelompok faktor yaitu Perencanaan, Pelaksanaan, dan Kebijakan/wewenang pemilik [3]. Adapun maksud dan tujuan dari penelitian yang dilakukan oleh peneliti adalah untuk engetahui apa saja kegiatan dalam proyek EPC, mengetahui kegiatan yang terkena dampak akibat keterlambatan di fase pelaksanaan proyek EPC, dan mengetahui cara untuk melakukan percepatan apabila terjadi keterlambatan proyek EPC pada fase pelaksanaan.

Teori merupakan himpunan konstruk (konsep), difinisi, dan preposisi yang mengemukakan pandangan sistematis tentang gejala dengan manjabarkan relasi di antara variabel, untuk menjelaskan dan meramalkan gejala tersebut [4]. Dari studi literatur tersebut dapat disimpulkan bahwa menurut [5], percepatan durasi dilakukan pada aktivitas-aktivitas pengikut dengan menambah jumlah jam kerja dan jumlah pekerja pada aktivitas percepatan.

Sebagai faktor novelty (keterbaruan penelitian) pada penelitian ini adalah, penelitian ini merupakan pengembangan dari penelitian terdahulu dengan konsep utama yaitu melakukan percepatan pada aktivitas proyek yang memungkinkan sehingga didapatkan tindakan korektif yang dapat dilakukan untuk mengatasi adanya keterlambatan durasi proyek pada suatu aktivitas.

Pemilihan objek ini dikarenakan langkah penyempurnaan dari proses manajemen proyek khusunya pada penjadwalan proyek yang menjadi faktor penting dalam laju produktivitas proyek.

\section{METODOLOGI PENELITIAN}

Dalam menjawab rumusan masalah, ada beberapa tahapan penelitian yang penulis lakukan sebagai berikut:

1. Survei

Strategi ini dilakukan untuk mendapatkan informasi dan mendata fenomena-fenomena yang terjadi pada sistem pengadaan, dan hubungan strukturalnya dengan kinerja pengadaan dalam mendapatkan konsultan yang berkualitas, dan penyelesaian pengadaan yang sesuai jadwal. Survei dilakukan pada populasi besar maupun kecil untuk mendapatkan jawaban atas pertanyaan apa, berapa banyak, dan berapa besar. Survei kueisioner kepada para pakar dan responden dilakukan untuk memvalidasi sistemvariabel yang akan diteliti apakah sudah tepat dalam menjawab rumusan masalah penelitian.

\section{Analisa Arsip}

Strategi penelitian ini penting dilakukan untuk mendapatkan jawaban atas pertanyaan apa, berapa banyak, dan berapa besar. Data-data yang ada, kemudian akan dianalisa dengan metode analisa yang penulis tentukan. Dengan melakukan proses tersebut, maka akan diperoleh pengembangan sistem pengadaan berbasis risiko yang lebih tepat. 
Vol. 8, No. 2, November 2019, P-ISSN: 2356-1491, E-ISSN: 2655-8211

DOI: https://doi.org/10.33322/forummekanika.v8i2.537

\section{Studi Kasus}

Studi kasus ini dilakukan untuk observasi dan menganalisa fenomena dari permasalahan sistem manajemen mutu untuk proses pengadaan jasa konsultansi. Dengan strategi ini diharapkan dapat menjawab pertanyaan bagaimana, dan mengapa atas suatu permasalahan yang diteliti.

\section{HASIL DAN PEMBAHASAN}

\subsection{Uraian kegiatan proyek EPC PLTU}

Berdasarkan temuan diketahui terdapat 4 fase pekerjaan proyek yaitu fase engineering, procurement, construction, dan start up \& commissioning yang diuraikan menjadi 5 level work breakdown structure (WBS) ditunjukkan pada Tabel 1.

Tabel 1. Uraian Pekerjaan Pada Proyek PLTU

\begin{tabular}{|c|c|c|}
\hline \multicolumn{3}{|r|}{ Uraian Pekerjaan } \\
\hline \multirow{3}{*}{$\begin{array}{l}\text { Project } \\
\text { Milestone }\end{array}$} & \multicolumn{2}{|c|}{ Contract Effective Date } \\
\hline & \multicolumn{2}{|c|}{ Comercial Operation Date Unit \#1 } \\
\hline & \multicolumn{2}{|c|}{ Comercial Operation Date Unit \#2 } \\
\hline \multirow[t]{11}{*}{ Engineering } & \multirow[t]{5}{*}{ Civil } & Site Preparation \\
\hline & & Piling, foundation, construction \& floor \\
\hline & & Turbine building \& control building \\
\hline & & Boiler steel structure \\
\hline & & Mescellaneous structure \\
\hline & \multirow[t]{5}{*}{ Mechanical } & Steam turbine \\
\hline & & Boiler steel structure \\
\hline & & Circulating water system \\
\hline & & Coal \& ash handling \\
\hline & & Balance of plant \\
\hline & Electrical & Electrical plant \\
\hline \multirow[t]{10}{*}{ Procurement } & \multirow[t]{4}{*}{ Civil } & Piling, foundation, construction \& floor \\
\hline & & Turbine building \& control building \\
\hline & & Boiler steel structure \\
\hline & & Miscellaneous structure \\
\hline & \multirow[t]{5}{*}{ Mechanical } & Steam turbine \& generator \\
\hline & & Boiler \\
\hline & & Circulating water system \\
\hline & & Coal \& ash handling \\
\hline & & Balance of plant \\
\hline & Electrical & Electrical plant \\
\hline
\end{tabular}


Tabel 1. Uraian Pekerjaan Pada Proyek PLTU (Lanjutan)

\begin{tabular}{|c|c|c|c|}
\hline \multicolumn{4}{|c|}{ Uraian Pekerjaan } \\
\hline \multirow[t]{27}{*}{ Construction } & \multirow[t]{27}{*}{ Civil } & \multirow[t]{3}{*}{ Site Preparation } & Mobilization \\
\hline & & & Design \\
\hline & & & $\begin{array}{l}\text { Site clearing, cut, filling, } \\
\text { levelling \&scope protect }\end{array}$ \\
\hline & & \multirow{15}{*}{$\begin{array}{l}\text { Piling, } \quad \text { foundation, } \\
\text { construction \& floor }\end{array}$} & Turbine building area $1 \& 2$ \\
\hline & & & $C W$ piping \\
\hline & & & Boiler plant area \#1 \& 2 \\
\hline & & & Intake \& discharge structure \\
\hline & & & $\begin{array}{l}\text { Circulating water system } \\
\text { area } \# 1 \& 2\end{array}$ \\
\hline & & & $\begin{array}{l}70 \mathrm{kV} \quad \text { switchyard \& } \quad \mathrm{S} / \mathrm{S} \\
\text { building }\end{array}$ \\
\hline & & & Workshop \& storage \\
\hline & & & Balance of plant area \\
\hline & & & Mosque \& gatehouse \\
\hline & & & Control room building \\
\hline & & & Diesel generator building \\
\hline & & & $\begin{array}{l}\text { Coal yard \& ash disposal } \\
\text { area }\end{array}$ \\
\hline & & & $\begin{array}{l}\text { Fire fighting, garage \& } \\
\text { parking area }\end{array}$ \\
\hline & & & Administration building \\
\hline & & & $\begin{array}{l}\text { Other works (earth work, } \\
\text { drain site road \& Etc) }\end{array}$ \\
\hline & & \multirow[t]{2}{*}{$\begin{array}{l}\text { Turbine building \& control } \\
\text { building }\end{array}$} & $\begin{array}{l}\text { Erection for steel structure } \\
\text { turbine building \& control } \\
\text { building }\end{array}$ \\
\hline & & & $\begin{array}{l}\text { Roof \& cladding turbine } \\
\text { building \& control building } \\
\text { unit \#1\&2 }\end{array}$ \\
\hline & & \multirow[t]{2}{*}{ Boiler steel structure } & $\begin{array}{l}\text { Erection for steel structure } \\
\text { boiler }\end{array}$ \\
\hline & & & $\begin{array}{l}\text { Roof \& cladding boiler unit } \\
\# 1 \& 2\end{array}$ \\
\hline & & \multirow[t]{5}{*}{ Miscellaneous structure } & $\begin{array}{l}\text { Warehouse, workshop, store } \\
\& \text { diesel generator building }\end{array}$ \\
\hline & & & Administration building \\
\hline & & & Gatehouse \& mosque \\
\hline & & & Balance \& plant building \\
\hline & & & Substation building \\
\hline
\end{tabular}


Vol. 8, No. 2, November 2019, P-ISSN: 2356-1491, E-ISSN: 2655-8211

DOI: https://doi.org/10.33322/forummekanika.v8i2.537

Tabel 1. Uraian Pekerjaan Pada Proyek PLTU (Lanjutan)

\begin{tabular}{|c|c|c|c|}
\hline \multicolumn{4}{|c|}{ Uraian Pekerjaan } \\
\hline \multirow[t]{27}{*}{ Construction } & \multirow[t]{24}{*}{ Mechanical } & \multirow[t]{7}{*}{ Steam turbine \& generator } & Overhead travelling crane \\
\hline & & & Install condenser \\
\hline & & & Install generator \\
\hline & & & Install steam turbine \\
\hline & & & $\begin{array}{l}\text { Install steam/ water cycle } \\
\text { equipment }\end{array}$ \\
\hline & & & Install aux, CW system \\
\hline & & & $\begin{array}{l}\text { Install electrical } \quad \& \\
\text { instrumentation works }\end{array}$ \\
\hline & & \multirow[t]{5}{*}{ Boiler } & Install stack \\
\hline & & & Install boiler \\
\hline & & & $\begin{array}{l}\text { Install other aux. equip } \\
(\text { Fans, EP, etc })\end{array}$ \\
\hline & & & Install piping \& ducting \\
\hline & & & $\begin{array}{l}\text { Install electrical } \quad \& \\
\text { instrumentation works }\end{array}$ \\
\hline & & \multirow[t]{3}{*}{ Circulating water system } & Install main $C W$ pipeline \\
\hline & & & Install pump \& screen \\
\hline & & & Install discharge pipe \\
\hline & & \multirow[t]{2}{*}{ Coal \& ash handling } & $\begin{array}{l}\text { Install coal \& ash handling } \\
\text { plant }\end{array}$ \\
\hline & & & $\begin{array}{lrl}\text { Install electrical } & \& \\
\text { instrumentation works } & \end{array}$ \\
\hline & & \multirow[t]{7}{*}{ Balance of plant } & Install water treatment plant \\
\hline & & & $\begin{array}{l}\text { Install waste water treatment } \\
\text { plant }\end{array}$ \\
\hline & & & Install water tanks \& oil tanks \\
\hline & & & Install reverse osmosis $(R O)$ \\
\hline & & & $\begin{array}{l}\text { Install electrical } \quad \& \\
\text { instrumentation works }\end{array}$ \\
\hline & & & Install compressed air plant \\
\hline & & & Install fire protection system \\
\hline & \multirow[t]{3}{*}{ Eelectrical } & \multirow[t]{3}{*}{ Electrical plant } & Install $70 \mathrm{kV}$ switchyard \\
\hline & & & $\begin{array}{l}\text { Install elec works ( } M V S W G \text {, } \\
M C C, P D C, \text { cable \& tray, etc) }\end{array}$ \\
\hline & & & $\begin{array}{l}\text { Install generator transf, aux, } \\
\text { transf town feeder transf }\end{array}$ \\
\hline
\end{tabular}


Tabel 1. Uraian Pekerjaan Pada Proyek PLTU (Lanjutan)

\begin{tabular}{|c|c|c|}
\hline \multicolumn{3}{|r|}{ Uraian Pekerjaan } \\
\hline \multirow{14}{*}{$\begin{array}{l}\text { Start up \& } \\
\text { commissioning }\end{array}$} & \multirow[t]{8}{*}{ Unit \#1 } & Start up of miscellaneous equipment \\
\hline & & Individual test \\
\hline & & System test periode \\
\hline & & Loading test \\
\hline & & Load rejection test \\
\hline & & Shut down \\
\hline & & 30 days reliability run \\
\hline & & Guarantee performance test \\
\hline & \multirow[t]{6}{*}{ Unit \#2 } & System test periode \\
\hline & & Loading test \\
\hline & & Load rejection test \\
\hline & & Shut down \\
\hline & & 30 days reliability run \\
\hline & & Guarantee performance test \\
\hline
\end{tabular}

Sumber: Olahan Penulis

\subsection{Kegiatan yang memiliki dampak akibat keterlambatan pada fase pelaksanaan}

Pada uji coba keterlambatan, diambil sampel salah satu kegiatan yang mengalami keterlambatan. Kegiatan konstruksi atau fase pelaksanaan diakhiri dengan kegiatan Install elec works (MV SWG, MCC, PDC, cable \& tray, etc). Uji coba dilakukan 4x pada kegiatan tersebut yaitu keterlambatan $0 \%, 25 \%, 50 \%$, dan $75 \%$. Dari hasil uji coba keterlambatan jadwal tersebut terdapat 20 uraian kegiatan yang terkena dampak sehingga termasuk didalam kegiatan kritis. Kegiatan tersebut adalah Engineering-civil-miscellaneous structure, Procurement-civil-miscellaneous structure, Construction-civil-miscellaneous structure-balance of plant buildings, Construction-civilmiscellaneous structure-sublation buildings, Construction-electrical-install elec work (MV SWG, MCC, PDC, cable\&tray, etc), Start up \& commissioning-unit \#1-Start up of miscellaneous equipment, Start up \& commissioning-unit \#1-individual test, Start up \& commissioning-unit \#1system test periode, Start up \& commissioning-unit \#1-loading test, Start up \& commissioning-unit \#1-load rejection test, Start up \& commissioning-unit \#1-shutdown, Start up \& commissioning-unit \#1-30 days reliability run, Start up \& commissioning-unit \#1-guarantee performance test, Start up \& commissioning-unit \#2-system test periode, Start up \& commissioning-unit \#2-loading test, Start up \& commissioning-unit \#2-load rejection test, Start up \& commissioning-unit \#2-shutdown, Start up \& commissioning-unit \#2-30 days reliability run, Start up \& commissioning-unit \#2-guarantee performance test.

\subsection{Pengembangan metode percepatan}

Metode percepatan penjadwalan dapat dilakukan dengan 2 cara yaitu: fast tracking dan crashing. Uji coba kembali dilakukan dengan mengidentifikasi kegiatan predecessor dan successor pada kegiatan yang mengalami keterlambatan. Hasil temuan menunjukkan bahwa construction-civilmiscellaneous structure-sublation buildings merupakan predecessor sedangkan start up \& commissioning-unit \#1-start up of miscellaneous equipment merupakan successor dengan hubungan kerja secara berurutan adalah SS (start to start) dan FF (finish to finish). 
Kegiatan construction-civil-miscellaneous structure-sublation buildings memiliki hubungan kerja start to start dengan kegiatan install elec works ( $M V S W G, M C C, P D C$, cable \& tray, etc). Kedua kegiatan tersebut tidak saling berhubungan dan dapat dilakukan secara pararel sehingga sebelumya telah dilakukan percepatan dengan cara fast tracking.

Kegiatan start up \& commissioning-unit \#1-start up of miscellaneous equipment memiliki hubungan kerja finish to finish yang artinya selesainya satu kegiatan mempengaruhi selesainya kegiatan lainnya sehingga apabila terjadi keterlambatan pada predecessor maka kegiatan tersebut akan mengalami keterlambatan. Kedua kegiatan tersebut dapat dilakukan percepatan dengan menggunakan fast tracking.

Selanjutnya dilakukan uji coba percepatan pada 2 kegiatan tersebut dengan percepatan $25 \%$, $50 \%$, dan $75 \%$. Dari hasil uji menunjukkan bahwa tidak dapat perubahan pada kegiatan kritis. Hal ini disebabkan karena jenis hubungan kerja yang merupakan start to start dan finish to finish.

\section{KESIMPULAN DAN SARAN}

Pengumpulan data dilakukan sesuai alur agar didapatkan hasil sesuai tujuan penelitian itu sendiri. Alur tersebut berjalan agar hasil dari setiap pengolahan data dapat menjadi input pengolahan selanjutnya. Kesimpulan dari penelitian ini adalah uraian kegiatan struktur yang diteliti telah sesuai dengan uraian pekerjaan pada proyek EPC PLTU, terdapat 4 fase kegiatan pada proyek EPC sulteng yang terdiri dari engineering, procurement, construction, dan start up \& commissioning yang diuraikan menjadi 5 level work breakdown structure (WBS), dari hasil uji coba keterlambatan jadwal tersebut terdapat 20 uraian kegiatan yang terkena dampak sehingga termasuk didalam kegiatan kritis. Kegiatan tersebut adalah Engineering-civil-miscellaneous structure, Procurement-civilmiscellaneous structure, Construction-civil-miscellaneous structure-balance of plant buildings, Construction-civil-miscellaneous structure-sublation buildings, Construction-electrical-install elec work (MV SWG, MCC, PDC, cable\&tray, etc), Start up \& commissioning-unit \#1-Start up of miscellaneous equipment, Start up \& commissioning-unit \#1-individual test, Start up \& commissioning-unit \#1-system test periode, Start up \& commissioning-unit \#1-loading test, Start up \& commissioning-unit \#1-load rejection test, Start up \& commissioning-unit \#1-shutdown, Start up \& commissioning-unit \#1-30 days reliability run, Start up \& commissioning-unit \#1-guarantee performance test, Start up \& commissioning-unit \#2-system test periode, Start up \& commissioningunit \#2-loading test, Start up \& commissioning-unit \#2-load rejection test, Start up \& commissioningunit \#2-shutdown, Start up \& commissioning-unit \#2-30 days reliability run, Start up \& commissioning-unit \#2-guarantee performance test.

Kegiatan construction-civil-miscellaneous structure-sublation buildings memiliki hubungan kerja start to start dengan kegiatan install elec works ( $M V$ SWG, MCC, PDC, cable \& tray, etc). Kedua kegiatan tersebut tidak saling berhubungan dan dapat dilakukan secara pararel sehingga sebelumya telah dilakukan percepatan dengan cara fast tracking. Kegiatan start up \& commissioningunit \#1-start up of miscellaneous equipment memiliki hubungan kerja finish to finish yang artinya selesainya satu kegiatan mempengaruhi selesainya kegiatan lainnya sehingga apabila terjadi keterlambatan pada predecessor maka kegiatan tersebut akan mengalami keterlambatan. Kedua kegiatan tersebut dapat dilakukan percepatan dengan menggunakan fast tracking. Dari hasil uji menunjukkan bahwa tidak dapat perubahan pada kegiatan kritis. Hal ini disebabkan karena jenis hubungan kerja yang merupakan start to start dan finish to finish.

Adapun beberapa saran yang diusulkan untuk penelitian selanjutnya adalah penelitian ini ditinjau hanya dari sudut pandang proyek PLTU Sulteng sebagai owner. Pada penelitian berikutnya dapat dilakukan dari sudut pandang yang berbeda, seperti melalui sudut pandang kontraktor dan 
pelaksana, penelitian ini hanya dilakukan pada proyek PLTU Sulawesi Tengah. Untuk penelitian berikutnya penelitian dapat dilakukan pada seluruh proyek EPC di Indonesia, Penelitian selanjutnya perlu identifikasi jumlah pekerja dan jam kerja proyek sehingga dapat dilakukan analisa dengan menggunakan RAM/RACI.

\section{DAFTAR PUSTAKA}

[1] Asiyanto. (2005). Manajemen Produksi untuk Jasa Konstruksi. Jakarta: Pradnya Paramita.

[2] Callahan, MT. (1992). Construction project scheduling. New York: McGrawHill.

[3] Rusman, dkk (2012). Faktor-Faktor Risiko Yang Mempengaruhi Kinerja Waktu Pelaksanaan Konstruksi Gedung Secara Swakelola (Studi Kasus: Proyek Pengembangan Sekolah Menengah Kejuruan di Provinsi Aceh). Banda Aceh: Universitas Syiah Kuala.

[4] Kerlinger.(1973). Asas-Asas Penelitian Behavioral. New York : Prentice Hall

[5] Alifen S, Ratna. (1999). Analisa"What If" Sebagai Metode Antisipasi Keterlambatan Durasi Proyek. Jakarta: Universitas Kristen Petra. 